\title{
Quantitative analysis of prediction models for hot cracking in industrial stainless steels using standardized requirements
}

\author{
A RODRÍGUEZ-PRIETO*, A M CAMACHO and M A SEBASTIÁN \\ Department of Manufacturing Engineering, College of Industrial Engineers, UNED, Juan del Rosal 12, \\ 28040 Madrid, Spain \\ e-mail: alvaro.rodriguez@invi.uned.es
}

MS received 3 May 2015; revised 5 June 2016; accepted 9 May 2017; published online 16 November 2017

\begin{abstract}
In this paper, a systematic analysis of different methods of $\delta$-ferrite estimation is carried out based on the well-known relationship between $\delta$-ferrite content and hot cracking in stainless steels. Additionally, the influence of certain chemical requirements on $\delta$-ferrite stabilization and their relationship to hot cracking is evaluated by the application of a deterministic algorithm based on stringency levels. The results obtained from the application of the stringency level method and prediction diagrams permit the selection of the best option among materials according to their standardized specifications. In addition, the advantage of this integrated method is that we can evaluate particular elemental influences and assign relative weightings to create a database for materials selection.
\end{abstract}

Keywords. $\delta$-Ferrite; hot cracking; prediction methods; stringency levels; decision tool.

\section{Introduction}

The field of materials research has seen phenomenal growth in recent years, assiduously accepting and assimilating ideas, concepts and analytical and experimental methodologies and demonstrating its remarkably multidisciplinary and interdisciplinary character. In this paper, a systematic analysis of different methods of $\delta$-ferrite estimation and elemental influence is performed for the most widely used austenitic stainless steels. These types of stainless steels are used in many industrial applications. The advantage of this type of steel is its high corrosion and oxidation resistance [1] due to the effect of the alloying elements on the formation of a passivating layer [2]. Nevertheless, austenitic stainless steels can be susceptible to hot cracking and stress corrosion cracking [3]. Hot cracking is a phenomenon that occurs at high temperatures along the grain boundaries in the heat-affected zone (HAZ) or in the dendrite limits of a welded metal [4] and appears when the stress during cooling exceeds the strength of a particular area of a welded joint. This lack of ductility depends on the microstructural characteristics and the presence of low melting point impurities.

A small amount of $\delta$-ferrite in the austenite reduces hot cracking [5]. Additionally, a small amount of $\delta$-ferrite mitigates the harmful effect of sulphur atoms trapped in the ferrite [6]. Several studies have focused on solidification mode prediction and estimation of the amount of $\delta$-ferrite

*For correspondence in stainless steels. In fact, the $\delta$-ferrite content (wt $\%$ ) can be estimated using well-recognized predictive methods [7]. These prediction models are based on the concepts of chromium and nickel equivalents calculated from the wt $\%$ of the most influential elements. To ensure the reproducibility of the results across laboratories, the U.S. Welding Research Council (WRC) introduced the Ferrite Number (FN) to define the amount of ferrite measured using a calibrated instrument [8].

It has been demonstrated that hot cracking increases when the values of the chromium and nickel equivalents are modified to obtain a purely austenitic structure without $\delta$ ferrite [9-12]. Likewise, nickel is an austenite stabilizer that strongly affects the subsequent phase transformation [13]. Generally, a minimum $\delta$-ferrite content of $3-4 \mathrm{FN}$ is considered to ensure the absence of hot cracking during solidification. Exceptions include some highly demanding applications, such as cladding processes for reactor pressure vessels (RPVs), for which a minimum $\delta$-ferrite content of 4-5 $\mathrm{FN}$ is often required [3].

Strauss and Maurer [14] introduced the first diagram for forecasting the metallographic phases of rolled stainless steels. Additionally, Newell and Fleischman [15] established a mathematical equation to describe the boundary between a pure austenitic microstructure and a mixed microstructure with $\delta$-ferrite content [7]. The first major contribution to the field of hot cracking prediction was developed by Schaeffler [16], as described in Eqs. (1) and (2): 


$$
\begin{gathered}
\mathrm{Ni}_{\mathrm{eq}}=\mathrm{Ni}+0.5 \mathrm{Mn}+30 \mathrm{C} \\
\mathrm{Cr}_{\mathrm{eq}}=\mathrm{Cr}+1.8 \mathrm{Mo}+2.5 \mathrm{Si}+2 \mathrm{Nb} .
\end{gathered}
$$

The chromium equivalent equation was modified by Seferian [17], as shown in Eqs. (3) and (4):

$$
\mathrm{Cr}_{\mathrm{eq}}=\mathrm{Cr}+\mathrm{Mo}+1.5 \mathrm{Si}+0.5 \mathrm{Nb} \text {. }
$$

The main differences between the original and modified Schaeffler equations are the new coefficients for the influence of molybdenum, silicon and niobium in the chromium equivalent equation.

De Long and Reid [18] studied the influence of nitrogen on the reduction of $\delta$-ferrite content in welded metals. The equations describing this process include Eqs. (4) and (5):

$$
\begin{aligned}
& \mathrm{Ni}_{\mathrm{eq}}=\mathrm{Ni}+0.5 \mathrm{Mn}+30 \mathrm{C}+30 \mathrm{~N} \\
& \mathrm{Cr}_{\text {eq }}=\mathrm{Cr}+\mathrm{Mo}+1.5 \mathrm{Si}+0.5 \mathrm{Nb} .
\end{aligned}
$$

Reid and De Long [8] presented a revised work that incorporated two ferrite scales. That year, Hull [19] presented Eqs. (6) and (7):

$$
\begin{aligned}
\mathrm{Ni}_{\mathrm{eq}}= & \mathrm{Ni}+0.11 \mathrm{Mn}-0.0086 \mathrm{Mn}^{2}+18.4 \mathrm{~N}+24.5 \mathrm{C} \\
& +0.41 \mathrm{Co}+0.44 \mathrm{Cu} \\
\mathrm{Cr}_{\mathrm{eq}}= & \mathrm{Cr}+1.21 \mathrm{Mo}+0.48 \mathrm{Si}+2.27 \mathrm{~V}+0.72 \mathrm{~W}+2.20 \mathrm{Ti} \\
& +0.14 \mathrm{Nb}+0.21 \mathrm{Ta}+2.48 \mathrm{Al} .
\end{aligned}
$$

Hull [19] added new coefficients and new elements, such as cobalt, copper, vanadium, tungsten, titanium, tantalum and aluminium. Nevertheless, this model has not been standardized or given the same recognition as those of Schaeffler or De Long. Some years later, Hammar and Svensson [20] presented Eqs. (8) and (9):

$$
\begin{aligned}
& \mathrm{Ni}_{\mathrm{eq}}=\mathrm{Ni}+0.31 \mathrm{Mn}+22 \mathrm{C}+14.2 \mathrm{~N}+\mathrm{Cu} \\
& \mathrm{Cr}_{\text {eq }}=\mathrm{Cr}+1.37 \mathrm{Mo}+1.5 \mathrm{Si}+2 \mathrm{Nb}+3 \mathrm{Ti} .
\end{aligned}
$$

According to this formula, the transition from the primary austenite (AF) to the primary ferrite (FA) mode occurs at a $\mathrm{Cr}_{\mathrm{eq}} / \mathrm{Ni}_{\mathrm{eq}}$ ratio of 1.55 . Additionally, Kujanpää [21] presented the following new equations:

$$
\begin{gathered}
\mathrm{Ni}_{\text {eq }}=30 \mathrm{C}+\mathrm{Ni}+0.5 \mathrm{Mn} \\
\mathrm{Cr}_{\text {eq }}=\mathrm{Cr}+\mathrm{Mo}+1.5 \mathrm{Si}+1.5 \mathrm{Nb} .
\end{gathered}
$$

Siewert et al [22] developed a new diagram for the prediction of $\delta$-ferrite content using a system of multivariable linear regressions. They published Eqs. (12) and (13):

$$
\begin{gathered}
\mathrm{Ni}_{\mathrm{eq}}=\mathrm{Ni}+35 \mathrm{C}+20 \mathrm{~N} \\
\mathrm{Cr}_{\mathrm{eq}}=\mathrm{Cr}+\mathrm{Mo}+0.7 \mathrm{Nb} .
\end{gathered}
$$

Brooks and Thompson [23] proposed that $\mathrm{Cr}_{\mathrm{eq}} / \mathrm{Ni}_{\mathrm{eq}}$ ratios greater than 1.5 render the metal immune to hot cracking. Kotecki and Sievert [24] made a modification to the WRC diagram, adding a new coefficient for copper in the nickel equivalent [see Eq. (14)] to improve the accuracy of the FN prediction, primarily in duplex stainless steels containing approximately $2 \%$ copper [7]. The $\delta$-ferrite wt $\%$ matches the FN up to 10 [25]. Equations (14) and (15) are as follows:

$$
\begin{gathered}
\mathrm{Ni}_{\mathrm{eq}}=\mathrm{Ni}+35 \mathrm{C}+0.25 \mathrm{Cu} \\
\mathrm{Cr}_{\mathrm{eq}}=\mathrm{Cr}+\mathrm{Mo}+0.7 \mathrm{Nb} .
\end{gathered}
$$

Based on Eqs. (14) and (15), in conventional welding processes, such as gas metal arc welding (GMAW) and shield metal arc welding (SMAW), the change in the solidification mode from primary austenite (AF) to primary ferrite (FA) occurs at a $\mathrm{Cr}_{\mathrm{eq}} / \mathrm{Ni}_{\mathrm{eq}}$ ratio between 1.4 and 1.5. Values $1.5<\mathrm{Cr}_{\mathrm{eq}} / \mathrm{Ni}_{\mathrm{eq}}<1.9$ correspond to the FA mode. A Cr $r_{\text {eq }} / \mathrm{Ni}_{\text {eq }}$ ratio greater than 2 also corresponds to a ferritic solidification mode [26].

The German nuclear committee (Kern Technischer Ausschuss-KTA) [27] adopted the De Long diagram [Eqs. (4) and (5)]. In the same year, Aström [28] published the following equation to calculate the FN directly:

$$
\begin{aligned}
\mathrm{FN}= & -48.53-13.85 \mathrm{C}+12.73 \mathrm{Si}+1.16 \mathrm{Mn} \\
& +3.89 \mathrm{Cr}-3.14 \mathrm{Ni}+4.60 \mathrm{Mo}+10.10 \mathrm{Cu}-20.36 \mathrm{~N} .
\end{aligned}
$$

The FNN-1999 [29] neural network model was presented in 1999 and offered a significant improvement in terms of accuracy over the WRC-1992 model. Further neural network models, such as the Oak Ridge Ferrite Number (ORFN) [30], provide improved accuracy through their use of nonlinear regression methods and cooling rate effects [7]. More recent works have been based on the influence of molybdenum on the ferrite content of stainless-steel welds [31], and others have been based on nonlinear mathematical equations [32, 33].

The models exhibit significant differences [34]. Therefore, the aim of this work is to perform a quantitative comparison of the most important models for predicting the $\delta$-ferrite wt $\%$ and to assess the suitability of different materials standards, such as the American and German standards, based on the analysis of the technological requirements. The standards analysed are the AISI 304 and AISI 347 specifications and their German equivalents.

\section{Prediction methods for current nuclear regulations}

Although there are many aspects of reactor safety, the safe operation of a nuclear reactor ultimately hinges on the structural integrity of the components [35]. Prediction 
models for structures have evolved over the years, reducing the $\delta$-ferrite estimation error. However, at present, in some specific fields of application, such as the nuclear sector, prediction models must be chosen based on specific national design codes [36]. This is the case for the manufacture of nuclear reactors: if the design code is the American code ASME B\&PV, the prediction model required is the WRC diagram. However, if the code is the German KTA, structural predictions should be performed using the De Long diagram (figure 1).

Though nuclear power plants are designed and constructed in conformity with existing stringent nuclear safety standards that ensure an adequate margin of safety [37], it is important to perform an assessment to identify the strengths and shortcomings of the nuclear power plants based on the requirements of the current standards [38] because nuclear energy continues to be an important part of the energy mix of several countries [39]. Therefore, these models are compared by applying a deterministic algorithm based on varying severity levels [40, 41].

Nevertheless, the most consolidated diagrams used to predict the structure of austenitic stainless steels are the De Long and WRC-1992 diagrams (figure 2). In fact, the WRC1992 diagram is the model for ferrite prediction recommended by the ASME B\&PV Code and by American nuclear regulations [42, 43]. Similarly, German KTA rules for RPV construction require the use of the De Long diagram [27].

Table 1 shows a comparison of both models, including the elements considered in the calculation of the chromium and nickel equivalents.

\section{Case study}

For a case study, we selected the AISI 304 and AISI 347 specifications and their German equivalents to analyse the most consolidated models for hot cracking prediction, i.e., the De
Long diagram and the WRC. For this study, we considered welding joints from identical materials. These materials were selected for the study because they are widely used in power stations [44] and many other demanding industrial applications.

\subsection{Approach}

Although major accidents such as Chernobyl or Fukushima have reinforced the need to further improve safety in the design of nuclear power plants, a combination of probabilistic and deterministic approaches should be implemented to minimize consequences in the public domain through enhancing safety margins and adding greater precision to quantitative accident prediction [45]. One deterministic methodology is the stringency level (SL) approach, which is recognized as a valuable decision tool in the selection of standardized materials specifications to prevent potential failures [3]. The method consists of assigning a quantifiable value (from 1 to 5 , where 5 is the maximum value) based on the stringency of each requirement using several equations that are shown in sections 3.3-3.5.

The equations are applied based on the type of requirement and its influence and whether an experimental limit from a key publication is considered [46]. Table 2 presents the three cases used in the methodology.

Table 3 shows the chemical requirements specified for AISI 304 and AISI 347 austenitic stainless steels and their German equivalents, DIN X5CrNi18-10 and DIN $\mathrm{X} 6 \mathrm{CrNiNb} 18-10$, respectively.

\section{$3.2 \delta$-Ferrite estimation}

Table 4 shows the FN according to Eqs. (4), (5), (14) and (15) from the De Long and WRC-1992 diagrams used to predict hot cracking.

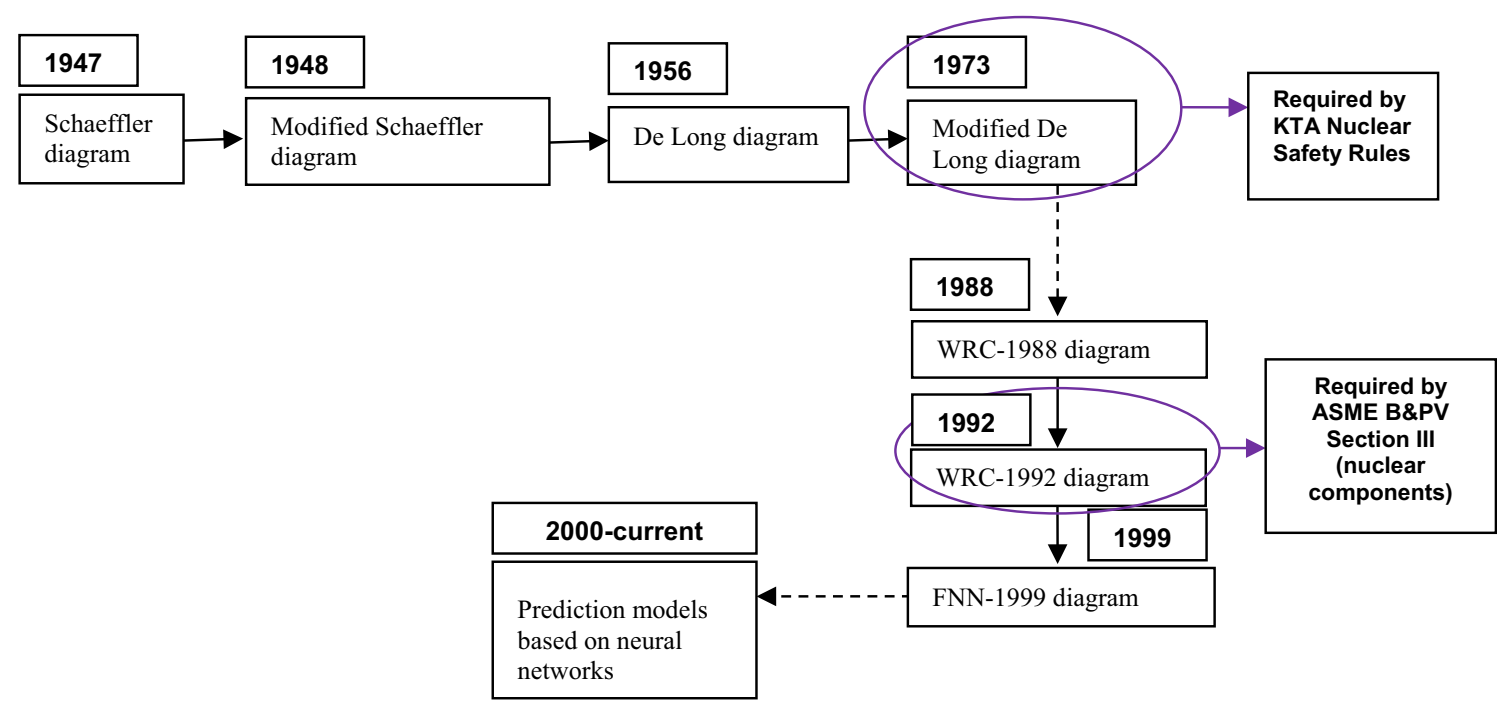

Figure 1. Evolution of different prediction models, and models required by current nuclear regulations. 

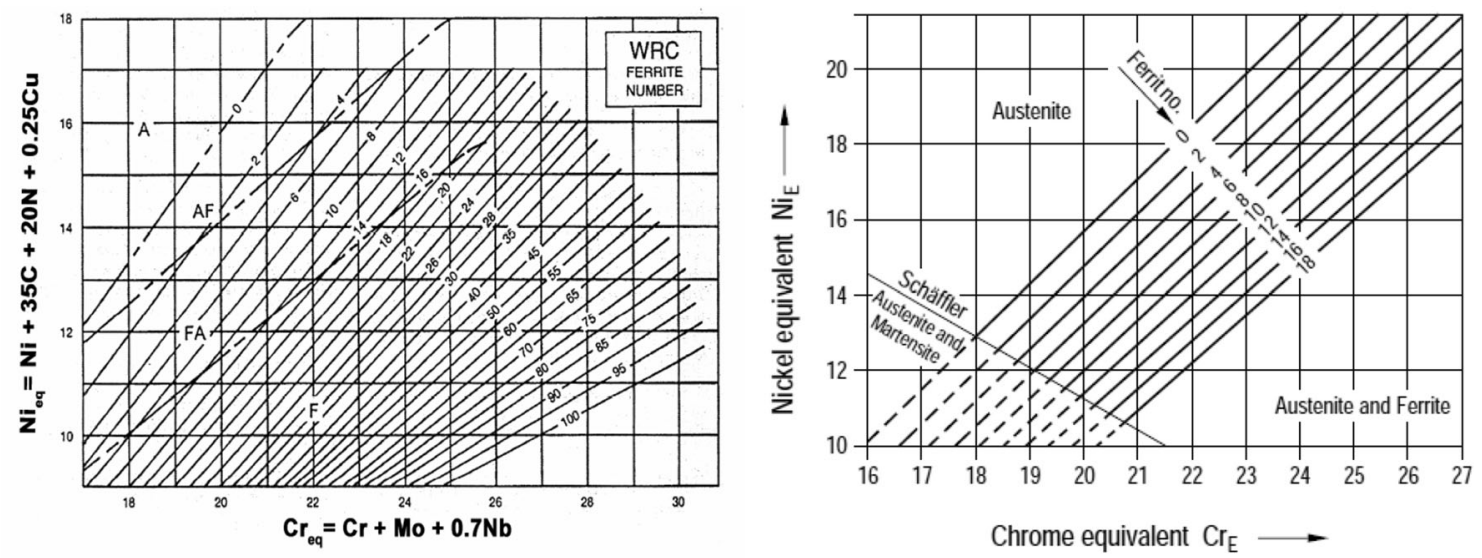

Figure 2. (a) WRC-1992 diagram [24] and (b) De Long diagram (KTA 3201.1 1998).

Table 1. Chemical elements in equations (based on [24, 27]).

\begin{tabular}{|c|c|c|c|c|c|c|c|c|c|}
\hline \multirow[b]{2}{*}{ Prediction model } & \multicolumn{5}{|c|}{ Ni equivalent equation } & \multicolumn{4}{|c|}{$\begin{array}{c}\mathrm{Cr} \text { equivalent } \\
\text { equation }\end{array}$} \\
\hline & $\mathrm{Ni}$ & $\mathrm{C}$ & $\mathrm{Mn}$ & $\mathrm{N}$ & $\mathrm{Cu}$ & $\mathrm{Cr}$ & Mo & $\mathrm{Si}$ & $\mathrm{Nb}$ \\
\hline De Long & $x$ & $\mathrm{x}$ & $x$ & $\mathrm{x}$ & & $\mathrm{x}$ & $\mathrm{x}$ & $\mathrm{x}$ & $\mathrm{x}$ \\
\hline WRC-1992 & $\mathrm{x}$ & $\mathrm{x}$ & & & $\mathrm{x}$ & $\mathrm{x}$ & $\mathrm{x}$ & & $\mathrm{x}$ \\
\hline
\end{tabular}

Table 2. Stringency level method cases.

Case Description

Case 0. General comparison of prediction methods

Case 1. Evaluation of chemical impurity requirements. No experimental limit considered

Case 2. Evaluation of chemical impurity requirements. Consideration of experimental limit

Case 3. Evaluation of alloyelement requirements
Before studying the individual influence of chemical elements on hot cracking, it is important to quantitatively evaluate the differences between the De Long and WRC diagrams

Case 1 is suitable for the evaluation of element requirements whose wt $\%$ should be low. It is used to evaluate phosphorous, sulphur and silicon content (equations are shown in section 3.3)

Case 2 is suitable for the evaluation of chemical impurity requirements when an experimental limit is considered. It is used to evaluate nitrogen content (equations are shown in section 3.4)

Case 3 is suitable for alloyelement requirement evaluation. It is used to evaluate carbon and manganese contents (equations are shown in section 3.5)
The obtained FN range is between 4 and 6 for DIN X6CrNiNb18-10 according to the De Long diagram, indicating that this material is more suitable with respect to hot cracking. AISI 347 and DIN X5CrNi18-10 exhibit FN values less than 2, whereas AISI 304 does not contain $\delta$-ferrite. In addition, DIN $\mathrm{X} 6 \mathrm{CrNiNb} 18-10$ is immune to hot cracking because the $\mathrm{Cr}_{\mathrm{eq}} / \mathrm{Ni}_{\mathrm{eq}}$ ratio is greater than 1.5. The $\mathrm{Cr}_{\mathrm{eq}} / \mathrm{Ni}_{\mathrm{eq}}$ ratio for the remaining materials is less than 1.5 , meaning that they are prone to hot cracking according to the Brooks and Thompson criterion [23].

According to the WRC-1992, the best choice is DIN $\mathrm{X} 6 \mathrm{CrNiNb} 18-10$ because it provides an $\mathrm{FN}$ value of 2-4. DIN X6CrNiNb18-10 provides an $\mathrm{FN}$ value of 4-6 according to the De Long diagram because of its silicon content, whereas WRC-1992 assigns an FN value of 2-4 to this material. DIN X6CrNiNb18-10 exhibits an austenitic structure with a $\delta$-ferrite content of approximately $5 \%$, which is beneficial because phosphorus, sulphur and silicon are dissolved more easily in ferrite than in austenite, reducing the influence of harmful impurities that segregate in the austenite grain edge. However, it is of greater importance to evaluate the phosphorous, sulphur and silicon content. To do so, the SL methodology is applied to this case study, as described in section 3.3.

\subsection{Influence and SL of phosphorus, sulphur and silicon}

Phosphorus, sulphur and silicon decrease resistance to hot cracking. Therefore, the calculation of SL of the phosphorus, sulphur and silicon requirements is developed according to Eqs. (18) and (19) using case 1 of the SL method, as shown in table 5.

Case 1 is suitable for the evaluation of element requirements whose wt\% should be low. The SLs are calculated according to Eqs. (17) and (18): 
Table 3. Chemical composition required for AISI 304, DIN X5CrNi18-10, AISI 347 and DIN X6CrNiNb18-10 [51, 52].

\begin{tabular}{lcccccccccc}
\hline & \multicolumn{7}{c}{ Chemical requirements (maximum wt\%) } \\
\cline { 2 - 9 } Specification & $\mathrm{C}$ & $\mathrm{Mn}$ & $\mathrm{Si}$ & $\mathrm{Cr}$ & $\mathrm{Ni}$ & $\mathrm{P}$ & $\mathrm{S}$ & $\mathrm{N}$ & $\mathrm{Nb}$ \\
\hline AISI 304 & 0.08 & 2.00 & 0.75 & $18.00-20.00$ & $8.00-10.50$ & 0.045 & 0.03 & 0.10 & - \\
DIN X5CrNi18-10 & 0.07 & 2.00 & 1.00 & $17.00-19.50$ & $8.00-10.50$ & 0.045 & 0.015 & 0.11 & - \\
AISI 347 & 0.08 & 2.00 & 0.75 & $17.00-19.00$ & $9.00-13.00$ & 0.045 & 0.03 & - & $10 \% \mathrm{C}-1.00$ \\
DIN X6CrNiNb18-10 & 0.04 & 2.00 & 1.00 & $17.00-19.00$ & $9.00-12.00$ & 0.035 & 0.015 & - \\
\hline
\end{tabular}

Table 4. $\mathrm{Cr}_{\mathrm{eq}}, \mathrm{Ni}_{\mathrm{eq}}$ and $\mathrm{FN}$ estimation according to the De Long and WRC-1992 diagrams.

\begin{tabular}{|c|c|c|c|c|c|c|c|c|}
\hline \multirow[b]{2}{*}{ Specification } & \multicolumn{4}{|c|}{ De Long diagram hot cracking prediction } & \multicolumn{4}{|c|}{ WRC-1992 diagram hot cracking prediction } \\
\hline & $\mathrm{Cr}_{\mathrm{eq}}$ & $\mathrm{Ni}_{\mathrm{eq}}$ & $\mathrm{Cr}_{\mathrm{eq}} / \mathrm{Ni}_{\mathrm{eq}}$ & FN & $\mathrm{Cr}_{\mathrm{eq}}$ & $\mathrm{Ni}_{\mathrm{eq}}$ & $\mathrm{Cr}_{\mathrm{eq}} / \mathrm{Ni}_{\mathrm{eq}}$ & FN \\
\hline AISI 304L & 20.13 & 15.65 & 1.29 & 0 & 19 & 14.05 & 1.35 & $0<\mathrm{FN}<2$ \\
\hline DIN X5CrNi18-10 & 19.75 & 15.65 & 1.25 & $0<\mathrm{FN}<2$ & 18.25 & 13.90 & 1.31 & 0 \\
\hline AISI 347 & 19.58 & 14.4 & 1.36 & $0<\mathrm{FN}<2$ & 18.63 & 13.8 & 1.35 & $0<\mathrm{FN}<2$ \\
\hline DIN X6CrNiNb18-10 & 19.83 & 12.7 & 1.56 & $4<\mathrm{FN}<6$ & 18.46 & 11.9 & 1.55 & $2<\mathrm{FN}<4$ \\
\hline
\end{tabular}

Table 5. Phosphorus, sulphur and silicon requirements and their stringency levels.

\begin{tabular}{|c|c|c|c|c|c|c|}
\hline Specification & $\begin{array}{l}\text { Maximum } \mathrm{P} \text { content } \\
\text { required }(\mathrm{wt} \%)\end{array}$ & $\begin{array}{l}\text { SL } \\
(\mathrm{P})\end{array}$ & $\begin{array}{l}\text { Maximum } S \text { content } \\
\text { required }(\mathrm{wt} \%)\end{array}$ & $\begin{array}{l}\text { SL } \\
(\mathrm{S})\end{array}$ & $\begin{array}{l}\text { Maximum } \mathrm{Si} \text { content } \\
\text { required (wt } \%)\end{array}$ & $\begin{array}{l}\mathrm{SL} \\
(\mathrm{Si})\end{array}$ \\
\hline AISI 304L & 0.045 & 5.00 & 0.030 & 2.00 & 0.75 & 5.00 \\
\hline DIN X5CrNi18-10 & 0.045 & 5.00 & 0.015 & 5.00 & 1.00 & 3.75 \\
\hline AISI 347 & 0.045 & 5.00 & 0.030 & 2.00 & 0.75 & 5.00 \\
\hline $\begin{array}{l}\text { DIN } \\
\text { X6CrNiNb18- } \\
10\end{array}$ & 0.035 & 5.00 & 0.015 & 5.00 & 1.00 & 3.75 \\
\hline
\end{tabular}

\section{$\mathrm{SL}=5.00$ for $\min \left\{L_{\mathrm{s}}\right.$ (AISI 304, AISI 347, DIN X5CrNi18-10 and DIN X6CrNiNb18-10)\}.}

The SLs of the other standard requirements are calculated according to Eq. (18):

$$
\mathrm{SL}=\frac{L_{\mathrm{s}(\min )}}{L_{\mathrm{S}}} \mathrm{SL}_{\max }
$$

where $L_{\mathrm{s}}$ is the limit specified by the standardized materials specification.

Using Eqs. $(18,19)$, the SLs of the phosphorus, sulphur and silicon requirements were calculated (as shown in table 5).

The sulphur requirements specified by DIN X5CrNi1810 and DIN X6CrNiNb18-10 are more stringent (5.00) than the requirements specified by AISI 304L and AISI 347 (2.00). Conversely, the silicon requirements specified by AISI 304L and AISI 347 are more stringent (5.00) than the requirements specified by DIN X5CrNi18-10 and DIN $\mathrm{X} 6 \mathrm{CrNiNb} 18-10$ (3.75). The phosphorous requirement is equal in all cases (5.00).

\subsection{Influence and SL of nitrogen content}

Nitrogen increases cracking susceptibility in the HAZ, irrespective of the level of sulphur. Matsuda [47] investigated cracking in welded steel AISI 304 with added nitrogen and concluded that nitrogen reduces the amount of primary and residual ferrite. Previously, Menon and Kotecki [48] concluded that a nitrogen content greater than $0.24 \%$ creates porosity in $18-8$ austenitic steels when they are welded [49]. Thus, the calculation is developed using case 2 of the SL method and Eqs. (19)-(23) [41], with the experimental limit considered $\left(L_{\mathrm{e}}\right)$ :

$$
\begin{gathered}
\mathrm{SL}=1.00 \quad\left(L_{\mathrm{s}} \geq L_{\mathrm{e}}\right) \text { or no limit is considered } \\
\mathrm{SL}=2.00 \quad\left(0.9 L_{\mathrm{e}} \leq L_{\mathrm{s}}<L_{\mathrm{e}}\right) \\
\mathrm{SL}=3.00 \quad\left(0.8 L_{\mathrm{e}} \leq L_{\mathrm{s}}<0.9 L_{\mathrm{e}}\right) \\
\mathrm{SL}=4.00 \quad\left(0.7 L_{\mathrm{e}} \leq L_{\mathrm{s}}<0.8 L_{\mathrm{e}}\right) \\
\mathrm{SL}=5.00 \quad\left(L_{\mathrm{s}}<0.7 L_{\mathrm{e}}\right)
\end{gathered}
$$

where $L_{\mathrm{e}}$ is equal to $0.24 \%$ [48] and $L_{\mathrm{s}}$ is the limit specified by the standardized materials specification. 
Table 6. Nitrogen requirement and its stringency level.

\begin{tabular}{lcc}
\hline Specification & $\begin{array}{c}\text { Maximum N content required } \\
(\text { wt } \%)\end{array}$ & SL(N) \\
\hline AISI 304 & 0.10 & 5.00 \\
DIN X5CrNi 18-10 & 0.11 & 5.00 \\
AISI 347 & - & 1.00 \\
DIN X6CrNiNb18- & - & 1.00 \\
$\quad 10$ & & \\
\hline
\end{tabular}

Table 6 shows the SL of the nitrogen requirement.

AISI 304 and DIN X5CrNi18-10 do not contain nitrogen; therefore, their SL assignment is the minimum value $(\mathrm{SL}=1.00)$.

\subsection{Influence and SLs of carbon and manganese content}

Hoerl and Moore [50] discovered that increases in the carbon or manganese content significantly reduce the sensitivity to cracking of AISI 347 steel. Thus, SL calculation of the carbon and manganese requirements is developed according to Eqs. (24) and (25) using case 3 of the SL method, as shown in table 7.

Case 3 [3] can be used to evaluate suitable alloy-element requirements [41]:

Table 7. Carbon and manganese requirements and their stringency levels.

\begin{tabular}{lcccc}
\hline & $\begin{array}{c}\text { Maximum C } \\
\text { content } \\
\text { required } \\
\text { (wt\%) }\end{array}$ & SL(C) & $\begin{array}{c}\text { Maximum } \\
\text { Mn content } \\
\text { required } \\
\text { (wt\%) }\end{array}$ & SL(Mn) \\
Specification & 0.08 & 5.00 & 2.00 & 5.00 \\
AISI 304 & 0.07 & 4.38 & 2.00 & 5.00 \\
DIN X5CrNi18- & & & & \\
$\quad 10$ & 0.08 & 5.00 & 2.00 & 5.00 \\
AISI 347 & 0.04 & 2.50 & 2.00 & 5.00 \\
DIN & & & & \\
$\quad$ X6CrNiNb18- & & & & \\
$\quad 10$ & & & & \\
\hline
\end{tabular}

$\mathrm{SL}=5.00$ for $\max \left\{L_{\mathrm{s}}\right.$ (AISI 304, AISI 347 ,

$$
\text { DIN X5CrNi18-10 and DIN X6CrNiNb18-10)\}. }
$$

The SLs of the remaining standard requirements are calculated as follows:

$$
\mathrm{SL}=\frac{L_{\mathrm{s}}}{L_{\mathrm{s}(\max )}} \mathrm{SL}_{(\max )}
$$

where $L_{\mathrm{s}}$ is the limit specified by the standardized materials specification.

The carbon requirements specified by AISI 304L and AISI 347 are more stringent (5.00) than the requirements specified by DIN X5CrNi18-10 (4.38) and DIN $\mathrm{X} 6 \mathrm{CrNiNb} 18-10$ (2.50). The manganese requirement is equal in all cases.

\section{Results and discussion}

Table 8 shows a comparison of the calculated SLs and the $\mathrm{Cr}_{\mathrm{eq}} / \mathrm{Ni}_{\mathrm{eq}}$ ratio and the $\mathrm{FN}$ estimation according to the De Long and WRC-1992 diagrams.

There are strong discrepancies between the WRC1992 and De Long estimations of $\delta$-ferrite for AISI 304L, DIN X5CrNi18-10 and DIN 18-10X6CrNiNb. This appears to be caused by differences in the calculation approach for $\mathrm{Cr}_{\mathrm{eq}}$ and $\mathrm{Ni}_{\mathrm{eq}}$; in the equations proposed by De Long, the silicon, manganese and nitrogen contents are considered, whereas they are not considered in the WRC-1992 diagram. In addition, WRC-1992 places greater weight on the niobium influence. Notably, the FN results obtained from the De Long and WRC-1992 diagrams exhibit a divergence between FN values 1 and 2 (figure 3).

Although this difference is only $1-2 \%$, such a difference may be significant when the acceptance criterion is between FN values 3 and 5, as is the case for several applications in the nuclear sector. However, the SLs of the element requirements for hot cracking susceptibility reveal that the values obtained for AISI 304 and DIN X5CrNi18-10 are slightly greater than the values for AISI 347 and DIN X6CrNiNb18-10 (figure 4), although the latter exhibit the greatest $\mathrm{Cr}_{\mathrm{eq}} / \mathrm{Ni}_{\text {eq }}$ ratio (see table 8). Therefore, according

\begin{tabular}{|c|c|c|c|c|c|c|c|c|c|c|}
\hline \multirow[b]{2}{*}{ Specification } & \multicolumn{6}{|c|}{ Stringency levels } & \multicolumn{2}{|c|}{ De Long diagram } & \multicolumn{2}{|c|}{ WRC-1992 diagram } \\
\hline & $\mathrm{P}$ & $\mathrm{S}$ & $\mathrm{Si}$ & $\mathrm{N}$ & $\mathrm{C}$ & Mn & $\mathrm{Cr}_{\mathrm{eq}} / \mathrm{Ni}_{\mathrm{eq}}$ & Medium value of FN & $\mathrm{Cr}_{\mathrm{eq}} / \mathrm{Ni}_{\mathrm{eq}}$ & Medium value of FN \\
\hline AISI 304L & 5.00 & 2.00 & 5.00 & 5.00 & 5.00 & 5.00 & 1.29 & 0 & 1.35 & 1 \\
\hline DIN X5CrNi18-10 & 5.00 & 5.00 & 3.75 & 5.00 & 4.38 & 5.00 & 1.25 & 1 & 1.31 & 0 \\
\hline AISI 347 & 5.00 & 2.00 & 5.00 & 1.00 & 5.00 & 5.00 & 1.36 & 1 & 1.35 & 1 \\
\hline DIN X6CrNi Nb18-10 & 5.00 & 5.00 & 3.75 & 1.00 & 2.50 & 5.00 & 1.56 & 5 & 1.55 & 3 \\
\hline
\end{tabular}

Table 8. Comparison of the obtained values. 


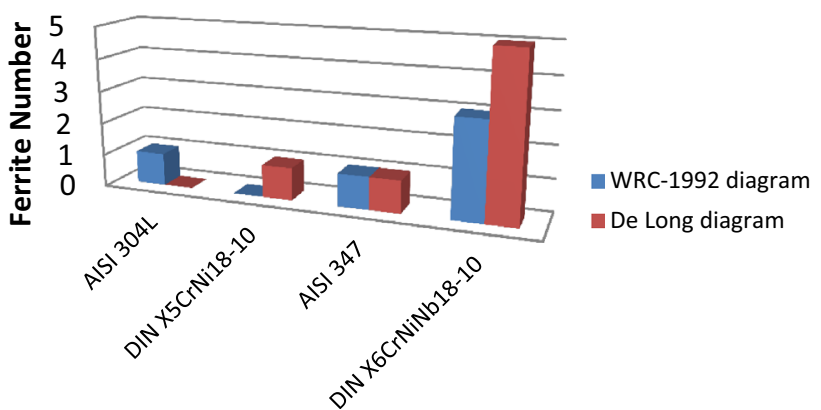

Figure 3. Calculation of the FN according to the WRC-1992 and De Long diagrams.

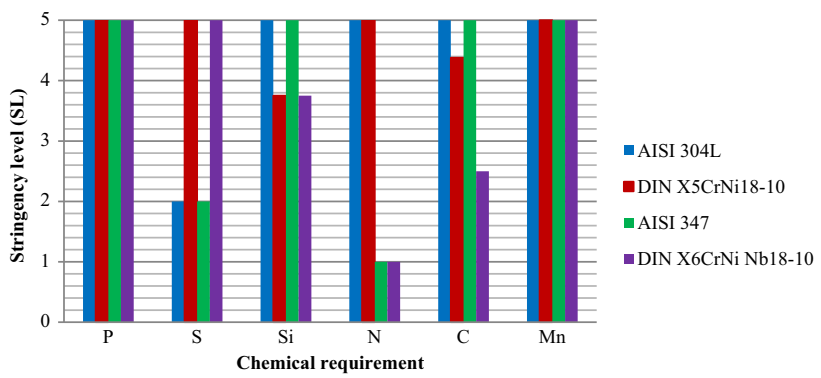

Figure 4. Representation of the obtained stringency levels.

to the criterion of Brooks and Thompson, which is a $\mathrm{Cr}_{\mathrm{eq}}$ / $\mathrm{Ni}_{\text {eq }}$ ratio greater than 1.5 , the DIN X6CrNiNb18-10 is immune to hot cracking. This result is confirmed by the De Long and WRC-1992 diagrams.

This divergence between the evaluations (SL method and diagrams) is due to AISI 304 and DIN X5CrNi18-10 not containing nitrogen and therefore being assigned the minimum $\mathrm{SL}$ value $(\mathrm{SL}=1.00)$.

\section{Conclusions and future work}

In this work, an analysis of the evolution of the most relevant prediction models of hot cracking in stainless steels was performed. Although recent models based on neural networks have improved the accuracy of classical models, some design codes require the use of consolidated models. This is the case for the American ASME B\&PV code, which specifies the use of the WRC diagram. Additionally, KTA rules require the use of the De Long diagram. These requirements are relevant in the manufacture of nuclear primary loops.

We observed that the FN results obtained for AISI 304L, DIN X5CrNi18-10 and DIN 18-10X6CrNiNb from the De Long and WRC-1992 diagrams exhibit a divergence that can become significant when the acceptance criterion is between FN values 3 and 5 for several applications in the nuclear sector. This appears to be due to differences in the calculation approach used for $\mathrm{Cr}_{\mathrm{eq}}$ and $\mathrm{Ni}_{\mathrm{eq}}$.
We applied a methodology based on the SLs of the requirements as a tool for selecting standardized materials specifications. In this application, we consider the influence of certain chemical elements on hot cracking and $\delta$-ferrite content (wt\%) as an indicator of the hot cracking susceptibility.

As a general conclusion, the results obtained from the application of the SL method and prediction diagrams support the selection of some materials according to their standardized specifications. In addition, the advantage of this integrated method is that we can evaluate particular elemental influences and assign relative weightings to create a database for materials selection.

Our plan for the future is to apply the methodology to different standardized materials specifications with industrial applications and examine previous selection requirements that have a greater influence on the mechanical behaviour of materials at high temperatures.

\section{Acknowledgements}

This work was financially supported by funds provided through the Annual Grant Call of the E.T.S.I.I. of UNED, Reference 2017-ICF04.

\section{References}

[1] Mahdavinejad R A and Saeedy S 2011 Investigation of the influential parameters of machining of AISI 304 stainless steel. Sadhana-Acad. Proc. Eng. Sci. 36(6): 963-970

[2] Priss J, Klevtsov I and Winkelmann H 2012 High-temperature chlorine corrosion in presence of sulphur containing and potassium external deposits. In: Annals of DAAAM for 2012 and Proceedings of the 23rd International DAAAM Symposium, 24-27 October, Zadar, Croatia, DAAAM International, pp. 911-916

[3] Rodríguez A, Camacho A M and Sebastián M A 2015 Prediction of the mechanical behaviour of cladding materials for nuclear reactor pressure-vessels based on the analysis of technological requirements. Proc. Eng. 100: 1301-1308

[4] ISO 17642-1 2004 Hot cracking test for weldments. Geneva: International Standards Organisation

[5] Moorhead A J, Sikka V K and Reed R W 1979 Effect of small additions of niobium on the welding behaviour of an austenitic stainless steel, properties of austenitic stainless steels and their weld metals (influence of slight chemistry variations). ASTM Special Technical Publication, vol. 679, pp. 103-111

[6] Chung H M, Perry D L and Shack W J 2003 Sulphur in austenitic stainless steel and irradiation assisted stress corrosion cracking. Houston: NACE International

[7] Valiente M A 2012 Predictive and measurement methods for delta ferrite determination in stainless steels. Weld. J. 91(4): 113-121

[8] Long C J and De Long W T 1973 The ferrite content of austenitic stainless steel weld metal. Weld. J. 52(7): 281-297 
[9] Borland J C and Younger R N 1980 Some aspects of cracking in welded $\mathrm{Cr}-\mathrm{Ni}$ austenitic steels. Br. Weld. J. 7: 22-59

[10] Cui Y and Lundin C D 2005 Effects of microfissures on mechanical properties of $308 \mathrm{~L}$ austenitic stainless steel weld metals. J. Mater. Sci. 40: 1281-1283

[11] Lundin C D, Chou C P D and Sullivan C J 1980 Hot cracking resistance of austenitic stainless steel weld metals. Weld. J. 59: 226-232

[12] Thomas R D 1946 Crack sensitivity of chromium-nickel stainless weld metal. Met. Prog. 50: 474-479

[13] Wu D Y, Han X L, Tian H T, Liao B and Xiao F R 2015 Microstructural characterization and mechanical properties analysis of weld metals with two Ni contents during postweld heat treatments. Metall. Mater. Trans. A 46: 1973-1984

[14] Strauss B and Maurer E 1920 Die Hochlegierten chromnickelstahle as nichtrostenden stahle. Kuppsche Monatsh. 1(8): 129-146

[15] Newell H D and Fleischmann M 1938 Hot rolled metal article and method of making same. U.S. Patent No. 2118 683

[16] Schaeffler A L 1947 Constitution diagram for stainless steel weld metal. Met. Prog. 56(11): 680-680

[17] Seferian D 1959 Metallurgie de la soudure. Paris: Dunod

[18] De Long W T and Reid H F 1957 Properties of austenitic chromiun in austenitic chromiun-manganese stainless steel weld metal. Weld. J. 37(1): 1-8

[19] Hull F C 1973 Delta ferrite and martensite formation in stainless steels. Weld. J. 51(5): 193-203

[20] Hammar O and Svensson U 1979 Influence of steel composition on segregation and microstructure during solidification of austenitic stainless steels. In: Solidification and casting of metals. London: The Metals Society

[21] Kujanpää V P 1979 Solidification cracking - estimation of the susceptibility of austenitic and austenitic-ferritic stainless steel weld. Met. Constr. 12(6): 282-285

[22] Siewert T A, McCowan C N and Olson D L 1988 Ferrite Number prediction to $100 \mathrm{FN}$ in stainless steel weld metal. Weld. J. 67(12): 289-298

[23] Brooks A and Thompson W 1991 Microstructural development and solidification cracking susceptibility of austenitic stainless steel welds. Int. Mater. Rev. 36: 16-44

[24] Kotecki D and Sievert T A 1992 WRC-1992 Constitution diagram for stainless steel weld metal: a modification of the WRC-1988 diagram. Weld. J. 71: 171-178

[25] Rao K R 2006 Companion guide to the ASME boiler \& pressure vessel code: criteria \& commentary select aspects ASME BPV \& piping codes, vol. I. New York: American Society of Mechanical Engineers

[26] Welding Handbook 2014 Materials and applications, part 2, vol. 4, 9th edn. Miami: American Welding Society

[27] KTA 3201.11998 Components of the reactor coolant pressure boundary of light water reactors, part 1: materials and product forms. Salzgitter: Nuclear Safety Standards Commission (KTA)

[28] Aström H 1998 Prediction of FN from chemical analysis. ELGA Technical Memo

[29] Vitek J M, lskander Y S and Oblow E M 2000 Improved ferrite number prediction in stainless steel arc welds using artificial neural networks-part 1: neural network development. Weld. J. 79(2): 33-40
[30] Vitek J M, lskander Y S and Oblow E M 2000 Improved ferrite number prediction in stainless steel arc welds using artificial neural networks-part 2: neural network results. Weld. J. 79(2): 41-50

[31] Anderson T, Perricone M J, DuPont J N and Marder A R 2007 The influence of molybdenum on stainless steel weld microstructures. Weld. J. 86(9): 281-292

[32] Kotecki D J and Zhang Z 2013 Sources of variation in ferrite number predictions vs. measurements. Weld. J. 92: $175-181$

[33] Valiente M A 2012 A mathematical model to predict $\delta$-ferrite content in austenitic stainless steel weld metals. Weld. World 56(9-10): 48-68

[34] Rodríguez-Prieto A 2014 Analysis of regulated requirements of materials and its influence on reactor pressure-vessels manufacturing for the nuclear industry (Análisis de requisitos tecnológicos de materiales especificados en normativas reguladas y su repercusión sobre la fabricación de recipientes especiales para la industria nuclear). $\mathrm{PhD}$ Dissertation, ETSII, UNED, Madrid

[35] Vaze K K 2013 Structural integrity aspects of reactor safety. Sadhana-Acad. Proc. Eng. Sci. 38(5): 971-997

[36] Rodríguez-Prieto A, Camacho A M and Sebastián M A 2016 Evaluation method for pressure vessel manufacturing codes: influence of ASME unit conversion. Int. J. Mater. Prod. Technol. 54(4): 259-274

[37] Vijayan P K, Kamble M T, Nayak A K, Vaze K K and Sinha R K 2013 Safety features in nuclear power plants to eliminate the need of emergency planning in public domain. Sadhana-Acad. Proc. Eng. Sci. 38(5): 925-943

[38] Bajaj S S 2013 Regulatory practices for nuclear power plants in India. Sadhana-Acad. Proc. Eng. Sci. 38(5): 1027-1050

[39] Grover R B and Puri R R 2013 Development of human resources for Indian nuclear power programme. SadhanaAcad. Proc. Eng. Sci. 38(5): 1051-1064

[40] Rodríguez-Prieto A, Camacho A M and Sebastián M A 2013 Proposal to quantify the efficacy of technological requirements of structural materials for the nuclear sector. In: Proceedings of the 17th International Congress on Project Management and Engineering, 17-19 July, Logroño, Spain, pp. $1324-1336$

[41] Rodríguez-Prieto A, Camacho A M and Sebastián M A 2016 Materials selection criteria for nuclear power applications: a decision algorithm. JOM 68(2): 496-506

[42] ASME Boiler and Pressure Vessel Code Section III, Division I 2013 Rules for construction of nuclear facility components. New York: The American Society of Mechanical Engineers

[43] Regulatory Guide 1.312013 Control of ferrite content in stainless steel weld metal. Revision 4. Washington: U.S. Nuclear Regulatory Commission

[44] Nebel T and Eifler D 2003 Cyclic deformation behaviour of austenitic steels at ambient and elevated temperatures. Sadhana-Acad. Proc. Eng. Sci. 28(1): 187-208

[45] Kakodkar A and Singh R K 2013 Integrated safety assessment of Indian nuclear power plants for extreme events: reducing impact on public mind. Sadhana-Acad. Proc. Eng. Sci. 38(5): 999-1025

[46] Rodríguez-Prieto A, Camacho A M and Sebastián M A 2016 New decision methodology for selecting manufacturing codes of nuclear reactor pressure-vessels. In: Annals of $D A A A M$ for 2015 and Proceedings of the 26th DAAAM 
International Symposium, 18-25 October, Zadar, Croatia, DAAAM International, pp. 693-698. https://doi.org/10.2507/ 26th.daaam.proceedings.095

[47] Matsuda F 1990 Hot crack susceptibility of weld metal. In: Advances in welding metallurgy. Doral, FL: American Welding Society (AWS), pp. 19-35

[48] Menon R and Kotecki D J 1989 Literature review - nitrogen in stainless steel weld metal. Weld. Res. Counc. Bull. 389: 142-161
[49] Shankar V, Gill T P S, Mannan S L and Sundaresan S 2003 Solidification cracking in austenitic stainless steel welds. Sadhana-Acad. Proc. Eng. Sci. 28: 359-382

[50] Hoerl A and Moore T J 1957 The welding of type 347 steels. Weld. J. 46: 442-448

[51] Bringas J E (Ed.) 2002 Handbook of comparative world steel standards. Philadelphia: American Society for Testings and Materials

[52] Stahlschlüssel 2013 Key to steel. Berlin: Verlag 